\title{
Influência da metileno-tetrahidrofolato redutase na patogênese das leucemias agudas infantis
}

\author{
Influence of the methylenetetrahydrofolate reductase in the pathogenesis of the \\ childhood acute leukemia
}

\author{
Crisiane Wais Zanrosso, ${ }^{1}$ Mariana Emerenciano, ${ }^{1}$ Alexandre Figueiredo,, Marcelo Reis, ${ }^{2}$ Synara Nô Seara Cordeiro, ${ }^{1}$ Alessandra Splendore, ${ }^{3}$ \\ Maria S Pombo-de-Oliveira'
}

\section{Resumo}

As leucemias resultam de uma interação adversa entre gene-ambiente, com susceptibilidade condicionada, pelo menos em parte, por polimorfismos de múltiplos genes. Como a metilenotetrahidrofolato redutase (MTHFR) possui papel chave no metabolismo do folato, alteraçōes na sua atividade (resultante de polimorfismos) ou alteraçôes na suplementação de folato, podem influenciar na síntese, reparo e metilação de DNA. Neste estudo, determinamos a freqüência dos polimorfismos $677 \mathrm{C}>\mathrm{T}$ e $1298 \mathrm{~A}>\mathrm{C}$ do gene $M T H F R$ em 177 crianças menores de 16 anos com leucemias agudas (LA) de diversas regiōes brasileiras e em 249 amostras de indivíduos normais como o grupo controle. O método utilizado para genotipagem foi PCR-RFLP. As freqüências dos genótipos 677CC, 677CT e 677TT foram 51\%, 40\% e 9\% nos controles, 57\%, 33\% e 10\% para os casos de leucemia linfoblástica aguda (LLA), e 49\%, 39\% e 12\% para os casos de leucemia mielóide aguda (LMA), respectivamente. Já as frequiências dos genótipos 1298AA, 1298AC e 1298CC foram respectivamente $62 \%$, 31\% e 7\% nos controles, 51\%, 41\% e $8 \%$ nos casos de LLA e, 67\%, 31\% e 2\% nos casos de LMA, respectivamente. Quando comparamos casos de LLA com os controles, para o polimorfismo $677 \mathrm{C}>\mathrm{T}$, encontramos um $\mathrm{OR}=0,7(0,5-1,2)$ e $\mathrm{OR}=1,0(0,4-2,1)$ para os genótipos CT e TT, respectivamente. Para o polimorfismo 1298A>C, o OR foi 1,6 (1,0 - 2,5) e 1,3 (0,6$3,0)$ para os genótipos AC e CC, respectivamente. Para os casos de LMA, o OR foi 1,0 $(0,5-2,1)$ para o genótipo CT, e 1,3 $(0,5$ - 3,9) para o genótipo TT. Para o genótipo AC, encontramos um $\mathrm{OR}=0,9(0,4-1,9)$; para o genótipo CC, o OR foi 0,3 (0,04 - 2,3). Não houve diferenças entre as freqüências do $M T H F R \quad 677 \mathrm{C}>\mathrm{T}$ e $1298 \mathrm{~A}>\mathrm{C}$ em ambos os grupos na análise global. Os resultados indicam que $M T H F R$ 677C > T e 1298A>C não conferem efeito protetor contra a LA infantil.

Palavras-chave: Leucemia aguda infantil; MTHFR; Polimorfismo.

\footnotetext{
${ }^{1}$ Divisão de Medicina Experimental, CPq - Instituto Nacional de Câncer, Rio de Janeiro.

${ }^{2}$ Divisão de Farmacologia, CPq - Instituto Nacional de Câncer, Rio de Janeiro.

${ }^{3}$ Divisão de Genética, CPq - Instituto Nacional de Câncer, Rio de Janeiro

Endereço para correspondência: Maria S Pombo-de-Oliveira. Instituto Nacional de Câncer. Coordenação de Pesquisa. Rua André Cavalcanti, 37

CEP: 20231-050. Rio de Janeiro - RJ, Brasil. E-mail: mpombo@inca.gov.br
} 


\section{Abstract}

ILeukemia is a result of an adverse gene-environment interaction, with a susceptibility related to polymorphisms. Since the methylenetetrahydrofolate reductase (MTHFR) plays a key role in folate metabolism, changes in its activity (resulting from polymorphisms) or changes in folate supply could influence DNA synthesis, repair and methylation. In this work, we have determined the frequency of MTHFR $677 \mathrm{C}>\mathrm{T}$ and $1298 \mathrm{~A}>\mathrm{C}$ polymorphisms in 177 children, with acute leukemia aged less than 16 years, from different regions of Brazil. Two hundred and fourty-nine region-matched subjects were the control group. PCR-RFLP method was used for genotyping. The frequencies for $677 \mathrm{CC}, 677 \mathrm{CT}$ and $677 \mathrm{TT}$ genotypes were $51 \%, 40 \%, 9 \%$ for controls; $57 \%, 33 \%, 10 \%$ for acute linfoblastic leukemia (ALL) cases, and 49\%, 39\%, 12\% for acute myeloid leukemia (AML) cases, respectively. The frequencies of MTHFR 1298AA, 1298AC, and 1298CC were 62\%, 31\%, 7\% for controls, 51\%, 41\%, 8\% for ALL cases, and $67 \%, 31 \%, 2 \%$ for AML cases, respectively. We compared cases and controls for $677 \mathrm{C}>\mathrm{T}$ polymorphism, the OR was $0,7(0,5-1,2)$ and $1,0(0,4-2,1)$ for CT and TT genotypes, respectively. The OR was $1,6(1,0-2,5)$ and $1,3(0,6-3,0)$ for AC and CC genotypes, respectively. In AML cases, the OR was $1,0(0,5-2,1)$ for CT genotype, and 1,3 $(0,5-3,9)$ for TT genotypes. The OR was $0,9(0,4-1,9)$ and $0,3(0,04-2,3)$ for AC and CC genotypes, respectively. No significant difference was observed when $M T H F R \quad 677 \mathrm{C}>\mathrm{T}$ and $1298 \mathrm{~A}>\mathrm{C}$ polymorphisms were compared between case and control groups. The statistical analysis suggests that MTHFR 677C $>\mathrm{T}$ and 1298A $>\mathrm{C}$ polymorphisms do not have a protective effect against childhood acute leukemia.

Key words: Childhood acute leukemia; MTHFR; Polymorphism.

\section{INTRODUÇÃO}

A leucemogênese é um processo multifatorial, resultante da combinação da exposição a fatores de risco ambientais e da susceptibilidade genética, como por exemplo, os polimorfismos genéticos. Assumindo que o efeito dos fatores externos é modulado por genes, os polimorfismos genéticos podem influenciar no risco individual ao câncer. ${ }^{1-3}$

As vias do metabolismo do ácido fólico têm sido alvo de várias pesquisas nos anos recentes. A enzima 5,10metileno-tetrahidrofolato redutase (MTHFR) é responsável pela redução da metileno-tetrahidrofolato (5,10-metilenoTHF) a metil-tetraidrofolato (5-metil-THF). O 5-metil-THF apresenta importante papel na metilação da homocisteína em metionina. A 5,10-metileno-THF e seus derivados são importantes na síntese de timina e purinas para a replicação do DNA. ${ }^{4,5}$ Portanto, alteraçōes na atividade da MTHFR, resultante de polimorfismos no gene MTHFR, podem modificar a susceptibilidade às transformaçōes malignas. $\mathrm{O}$ esquema delineado na Figura 1 demonstra a possível via alternativa do aproveitamento do folato no metabolismo sob influência dos polimorfismos.

Dois polimorfismos do gene MTHFR: a variante $\mathrm{T}$ no nucleotídeo 677 (MTHFR 677C>T) e a variante C no nucleotídeo 1298 (MTHFR 1298A>C) estão associadas com a redução da atividade enzimática, e alteração na distribuição intracelular de folato. Nos estudos de genética populacional já foi demonstrado que a freqüência destes alelos varia consideravelmente entre os diversos grupos raciais, étnicos e geográficos. ${ }^{6}$

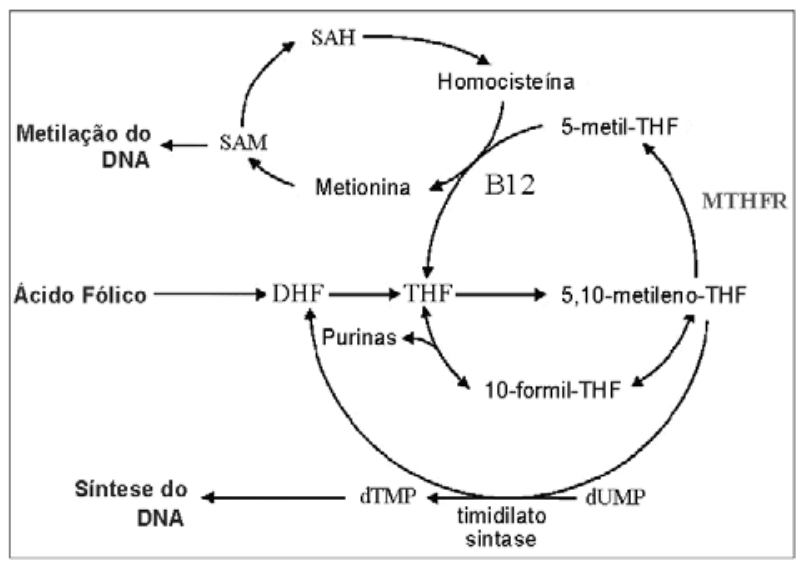

Figura 1. Metabolismo do ácido fólico e função da MTHFR.

Vários estudos epidemiológicos moleculares mostram resultados divergentes entre a associação destes polimorfismos e o risco às neoplasias. ${ }^{7-9}$ No que diz respeito as hemopatias, Skibola et al. analisaram a influência dos polimorfismos do gene MTHFR em adultos com leucemia linfoblástica aguda (LLA) e leucemia mielóide aguda (LMA), e observaram que os genótipos 677TT, 1298AC e 1298CC diminuíram o risco de ocorrência de LLA, mas não de LMA. ${ }^{4}$ Em contra partida, Wielmels et al. descreveram um efeito protetor do polimorfismo $677 \mathrm{C}>\mathrm{T}$ nas leucemias agudas que afetam lactentes (crianças menores de 2 anos de idade) com rearranjo do gene MLL.10 Krajinovic et al. mostraram um efeito protetor dos alelos polimórficos do gene MTHFR apenas em crianças que nasceram antes da implementação do programa de suplementação de folato 
durante a gravidez. ${ }^{1}$ Recentemente, Chiusolo et al. analisaram 174 italianos adultos com LLA, e não encontraram nenhuma associação entre os diferentes polimorfismos e a susceptibilidade a LLA. ${ }^{11}$

No Brasil existe uma escassez de dados sobre a freqüência dos alelos polimórficos $677 \mathrm{C}>\mathrm{T}$ e $1298 \mathrm{~A}>\mathrm{C}$ do gene MTHFR. Este trabalho pretende contribuir para a melhor compreensão dos mecanismos moleculares envolvidos no processo de leucemogênese infantil, estabelecendo a frequêencia dos alelos polimórficos do gene MTHFR, e a sua influência na patogênese da leucemia aguda (LA) infantil de crianças provenientes de diversas regiōes brasileiras.

\section{MATERIAL E MÉTODOS}

AMOSTRAS. Foram analisadas 177 amostras de sangue periférico/medula óssea de pacientes portadores de LA de $0-16$ anos, procedentes de diversos estados brasileiros, isentos de tratamento prévio. Todas as amostras foram classificadas pelos métodos de imunofenotipagem e citogenética molecular, conforme descrito por Pui. ${ }^{12}$ Estas amostras fazem parte de um estudo cooperativo entre diversos centros de tratamento de leucemias infantis com o projeto: "Estudo imuno-molecular e patogênese das leucemias que afetam o lactente no Brasil". Portanto, os casos analisados neste estudo foram derivados principalmente de 4 regiōes geográficas brasileiras: 1) Região Sul; 2) Região Sudeste; 3) Região Nordeste; 4) Região Centro-Oeste. Para as diferenças raciais, foram considerados dois grupos, de acordo com a cor da pele. A definição de cor branca e não-branca foi baseada na informação proveniente do próprio paciente, de acordo com a sua própia denominação. Os subtipos de LA estudados foram: LLA de células precursoras B (BpALL), LLA de células T (LLA-T) e LMA. O grupo controle foi constituído por amostras de crianças de 0-16 anos ( $n=144)$, e amostras de sangue de cordão umbilical $(\mathrm{n}=105)$, sem diagnóstico de leucemia, e procedentes das mesmas regiōes dos casos. GENOTIPAGEM. A análise do DNA dos grupos caso e controle foram feitos através da técnica de PCR-RFLP. As regiōes contendo ambos os polimorfismos foram amplificadas separadamente. Os primers P1 (CCTTGAACAGGTGGAGGCC) e P2 (CAAAGAAAAAGCTGCGTGATGAT) foram usados para amplificar o polimorfismo 677. Para o polimorfismo 1298, foram usados os primers P3 (GCAAGTCCCCCAAGGAGG) e P4 (GGTCCCCACTTCCAGCATC). Os amplicons foram digeridos com Hinf I (para o polimorfismo 677C $>\mathrm{T}$ ) ou Mbo II (para o polimorfismo 1298A>C), e visualizados por eletroforese em gel de agarose 2,2\%, conforme esquematizado na Figura 2.
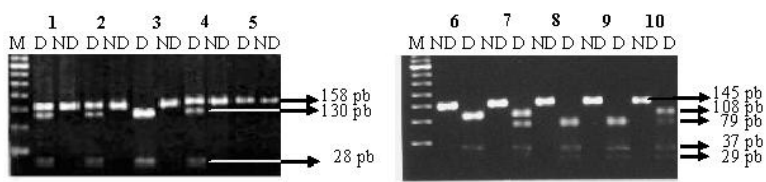

Figura 2. Visualização dos padrões polimórficos em gel de agarose. $\mathrm{M}$ : marcador 50pb; ND: amostra não digerida; $\mathrm{D}$ : amostra digerida; 1,2 e 4: amostras com padrão heterozigoto (677CT); 3: amostra com padrão mutante (677TT); 5: amostra com padrão homozigoto selvagem (677CC); 6: amostra com padrão homozigoto mutante (1298CC); 7 e 10: amostras com padrão heterozigoto (1298AC); 8 e 9: amostras com padrão homozigoto selvagem (1298AA).

ANÁLISE ESTATÍSTICA. Todas as análises de freqüência das variáveis e correlações foram feitas utilizando o pacote estatístico SPSS (versão 11.0). A significância estatística entre os diferentes grupos estudados foi calculada utilizando o teste exato de Fisher (two-sided). Para a razão de produtos cruzados foi utilizado um intervalo de confiança de $95 \%$. Uma análise logística das multi-variáveis foi realizada separadamente. Idade, gênero e região foram incluídos como co-variáveis em todos os genótipos estudados e suas possíveis interações.

\section{RESULTADOS}

O grupo caso foi constituído por 126 crianças com BpALL, na sua maioria CD10+, 6 com LLA-T e 45 com LMA. A média de idade foi de 4 anos, sendo que 14 crianças tinham idade inferior a 3 meses, e 69 crianças com idade superior a 24 meses. Não houve diferenças em relação à faixa etária, sexo e subtipos de LA nas diferentes regiōes brasileiras. As principais características clínicas e demográficas dos casos estudados são mostradas na Tabela 1 . O alelo 677T foi observado em $42 \%$ dos casos de LLA, $51 \%$ dos casos de LMA, e em 48\% dos controles. O alelo C1298 foi observado em 49\% dos casos de LLA, 33\% dos casos de LMA, e em 38\% dos controles. A Tabela 2 mostra a distribuição dos genótipos dos polimorfismos MTHFR $677 \mathrm{C}>\mathrm{T}$ e $1298 \mathrm{~A}>\mathrm{C}$ em pacientes com LLA, LMA, e no grupo controle. A freqüência dos genótipos MTHFR 677CC, 677CT e 677TT foi de 57\%, 33\%, 10\% nos casos de LLA, 49\%, 39\%, 12\% nos casos de LMA, e $51 \%, 40 \%, 9 \%$ nos controles, respectivamente. A frequiência dos genótipos MTHFR 1298AA, 1298AC e $1298 \mathrm{CC}$ foi de $51 \%, 41 \%, 8 \%$ nos casos de LLA, $67 \%$, $31 \%$, 2\% nos casos de LMA, e 62\%, 31\%, 7\% nos controles, respectivamente. Quando comparamos o alelo 
Tabela 1. Características clínicas e demográficas dos pacientes com LA e dos indivíduos sadios.

\begin{tabular}{|c|c|c|c|}
\hline Características & $\begin{array}{c}\text { Grupo Casos } \\
\text { (n) }\end{array}$ & $\begin{array}{c}\text { Grupo Controle } \\
\text { (n) }\end{array}$ & $P$ \\
\hline Número Total & 177 & 249 & \\
\hline Média de Idade (meses): & 48 & 42 & NS \\
\hline $0-3$ & 14 & 114 & \\
\hline $4-12$ & 42 & 11 & \\
\hline $13-24$ & 52 & 10 & \\
\hline$\geq 25$ & 69 & 114 & \\
\hline Sexo: & & & NS \\
\hline Masculino & 93 & 127 & \\
\hline Feminino & 84 & 122 & \\
\hline Cor de Pele: & & & NS \\
\hline Branca & 86 & 146 & \\
\hline Não Branca & 91 & 103 & \\
\hline \multicolumn{4}{|l|}{ Leucemias Agudas: } \\
\hline BpALL & 126 & - & \\
\hline LLA-T & 6 & - & \\
\hline AML & 45 & - & \\
\hline \multicolumn{4}{|l|}{ Regiões Brasileiras: } \\
\hline Sul $(n=79)$ & 22 & 57 & NS \\
\hline Sudeste $(n=174)$ & 92 & 82 & NS \\
\hline Centro-oeste $(n=31)$ & 17 & 14 & NS \\
\hline Nordeste $(n=142)$ & 46 & 96 & NS \\
\hline
\end{tabular}

Abreviaçôes: BpALL= leucemia linfoblástica aguda de células precursoras B; LLA-T= leucemia linfoblástica aguda de células T; LMA= leucemia mieloblástica aguda; $\mathrm{n}=$ número de casos; NS= sem significado estatístico.

Tabela 2. Distribuição dos genótipos do gene MTHFR.

\begin{tabular}{c|c|c|c|c|c|c}
\hline & MTHFR & LLA & LMA & Controles & $\begin{array}{c}\text { LLA versus } \\
\text { Controle }\end{array}$ & $\begin{array}{c}\text { LMA versus } \\
\text { Controle }\end{array}$ \\
\hline Polimorfismo & & $\mathrm{n}(\%)$ & $\mathrm{n}(\%)$ & $\mathrm{n}(\%)$ & OR (IC 95\%) & OR (IC 95\%) \\
\hline \multirow{3}{*}{$677 \mathrm{C}>\mathrm{T}$} & $\mathrm{CC}$ & $70(57)$ & $21(49)$ & $123(51)$ & $1.0^{*}$ & $1.0^{*}$ \\
& $\mathrm{CT}$ & $40(33)$ & $17(39)$ & $95(40)$ & $0,74(0,5-1,2)$ & $1,0(0,5-2,1)$ \\
& $\mathrm{TT}$ & $12(10)$ & $5(12)$ & $22(9)$ & $1,0(0,4-2,1)$ & $1,3(0,5-3,9)$ \\
\hline $1298 \mathrm{~A}>\mathrm{C}$ & AA & $64(51)$ & $28(67)$ & $151(62)$ & $1.0^{*}$ & $1.0^{*}$ \\
& AC & $51(41)$ & $13(31)$ & $77(31)$ & $1,6(1,0-2,5)$ & $0,9(0,4-1,9)$ \\
& CC & $10(8)$ & $1(2)$ & $18(7)$ & $1,3(0,6-3,0)$ & $0,3(0,04-2,3)$ \\
\hline
\end{tabular}

Teste de interação: $\mathrm{p}=0,774$ para o polimorfismo $677 \mathrm{C}>\mathrm{T} ; \mathrm{p}=0,118$ para o polimorfismo $1298 \mathrm{~A}>\mathrm{C} \mathrm{n}=$ número de casos; $\mathrm{OR}=$ razão de chance, foi calculado usando regressão logística; $(*)=$ Grupo de referência.

677T com o genótipo 677CC, não encontramos evidências estatísticas de associação entre o alelo mutante e a diminuição do risco de LLA (OR 0,7, 95\% IC 0,51,2 para 677CT, e OR 1,0, 95\% IC 0,4-2,1 para 677TT) ou LMA (OR 1,0, 95\% IC 0,5-2,1 para 677CT, e OR
1,3, 95\% IC 0,5-3,9 para 677TT). Similarmente, não encontramos associação estatisticamente significativa entre o alelo $1298 \mathrm{C}$ e a diminuição do risco de LLA (OR $1,6,95 \%$ IC $1,0-2,5$ para 1298 AC, e OR $1,3,95 \%$ IC 0,6-3,0 para 1298CC) ou LMA (OR 0,9, 95\% IC 0,4- 
1,9 para $1298 \mathrm{AC}$, e OR $0,3,95 \%$ IC $0,04-2,3$ para 1298CC), quando comparado com o genótipo 1298AA.

O efeito combinado dos polimorfismos também foi analisado, conforme mostrado na Tabela 3 . O teste exato de Fisher não mostrou associação estatisticamente significativa entre os genótipos associados e a magnitude ou risco de leucemogênese. O genótipo duplo homozigoto selvagem [677CC/1298AA] foi encontrado em 26 casos de LLA, 11 de LMA, e 57 controles, respectivamente. A combinação dos genótipos heterozigoto e selvagem [677CC/1298AC; 677CT/ 1298AA] foi encontrada em 55 casos de LLA, 17 de LMA, e 113 controles, respectivamente. A associação do duplo heterozigoto [677CT/1298AC] foi encontrada em 14 casos de LLA, 1 de LMA, e 27 controles, respectivamente. A combinação dos genótipos 677CT/ 1298CC só foi encontrada em 3 controles, enquanto a combinação dos genótipos 677TT/1298AC foi encontrada apenas em um caso de LMA. O restante dos pacientes apresentou a combinação de genótipos 677TT/1298AA ou 677CC/1298CC. Nenhum indivíduo apresentou o genótipo duplo homozigoto mutante [677TT/1298CC]. O teste de Fisher indica que há uma associação entre as variáveis $677 \mathrm{C}>\mathrm{T}$ e $1298 \mathrm{~A}>\mathrm{C}$ $(\mathrm{p}<0,001)$, de forma que os indivíduos que são heterozigotos ou mutantes em uma variável tendem a ser selvagem na outra. A Tabela 4 mostra a distribuição dos polimorfismos 677C > T e 1298A $>$ C do gene MTHFR nas diversas regiôes brasileiras. Não houve diferenças na frequiência dos genótipos, entre casos e controles, nas diferentes regiōes estudadas $[p=0,1$ para os casos, e $p=$ 0,5 para os controles, para o polimorfismo $677 \mathrm{C}>\mathrm{T} ; p=$ 0,6 para os casos; $p=0,05$ para os controles].

\section{DISCUSSÃO}

Muitos estudos têm apresentado resultados divergentes sobre a importância dos polimorfismos do gene MTHFR no risco da leucemogênese e sua associação com o nível de utilização de folato em diferentes populaçôes. Cada etapa do ciclo do folato regula a disponibilidade dos substratos de folato, e as

Tabela 3. Análise dos polimorfismos C677T e A1298C do gene MTHFR nos casos de LLA.

\begin{tabular}{c|c|c|c|c|c}
\hline \multicolumn{2}{c|}{ Genótipos MTHFR } & LLA & Controle & LLA versus Controle & $P$ \\
\hline $677 C T$ & $1298 A C$ & $\mathrm{n}(\%)$ & $\mathrm{n}(\%)$ & OR (IC 95\%) & \\
\hline CC & AA & $26(23)$ & $57(24)$ & $1,0 *$ & - \\
\hline CC & AC & $30(26,3)$ & $49(20,7)$ & $1,342(0,7-2,6)$ & 0,411 \\
\hline CC & CC & $10(8,8)$ & $15(6,3)$ & $1,462(0,6-3,7)$ & 0,472 \\
\hline CT & AA & $25(21,9)$ & $64(27)$ & $0,856(0,4-1,6)$ & 0,739 \\
\hline CT & AC & $14(12,3)$ & $27(11,4)$ & $1,137(0,5-2,5)$ & 0,839 \\
\hline CT & CC & 0 & $3(1,3)$ & - & 0,550 \\
\hline TT & AA & $9(7,9)$ & $22(9,3)$ & $0,897(0,4-2,2)$ & 1 \\
\hline
\end{tabular}

*Grupo de referência; $\mathrm{n}=$ número de casos.

Tabela 4. Distribuição dos polimorfismos 677 C > T e 1298A>C do gene MTHFR nas diversas regiões brasileiras.

\begin{tabular}{l|c|c|c|c|c|c|c|c|c|c|c|c}
\hline & \multicolumn{4}{|c|}{677 C $>$ T } & \multicolumn{4}{c}{ 1298A $>$ C } \\
\hline Região & \multicolumn{4}{|c|}{ Casos (\%) } & \multicolumn{3}{c|}{ Controle (\%) } & \multicolumn{3}{c}{ Controle (\%) } \\
\hline & CC & CT & TT & CC & CT & TT & AA & AC & CC & AA & AC & CC \\
\hline S & 48 & 43 & 9 & 52 & 36 & 12 & 39 & 50 & 11 & 52 & 40 & 8 \\
\hline SE & 56 & 36 & 8 & 55 & 38 & 7 & 57 & 35 & 8 & 52 & 37 & 11 \\
\hline CO & 34 & 53 & 13 & 29 & 57 & 14 & 56 & 37 & 7 & 72 & 28 & 0 \\
\hline NE & 66 & 21 & 15 & 51 & 41 & 8 & 58 & 39 & 3 & 75 & 20 & 5 \\
\hline
\end{tabular}

$\mathrm{S}=$ região sul; $\mathrm{SE}=$ região sudeste; $\mathrm{CO}=$ região centro-oeste; $\mathrm{NE}=$ região nordeste; $\mathrm{n}=$ número de casos; $677 \mathrm{C}>\mathrm{T}$ - caso: $p=0,1 ;$ controle: $p=0,5$; $\mathrm{n}=$ número de casos. $1298 \mathrm{~A}>\mathrm{C}-$ caso: $p=0,6$; controle: $p=0,05$. 
formas variantes podem contribuir para a estabilidade do DNA. ${ }^{6}$ Resultados conflitantes entre estudos que investigam os polimorfismos do gene MTHFR e o risco das várias formas de câncer podem ser devido a pouca informação sobre o aporte de folato na dieta. Em 2001, Thompsom et al. realizaram um estudo investigativo sobre os possíveis fatores de risco para LLA infantil. As análises deste estudo indicaram que a suplementação de folato durante a gestação reduziu o risco de leucemias agudas $[\mathrm{OR}=0,4(0,2-0,7)]$, e que o efeito protetor dos polimorfismos da MTHFR é dependente do aporte de folato adequado. Neste trabalho, eles também evidenciaram que a incidência de LLA infantil diminuiu após a campanha para promover a suplementação de folato durante a gravidez. ${ }^{13}$ Além deste estudo australiano, Bailey relatou que o baixo nível nutricional de folato representa um risco aumentado para o desenvolvimento de câncer. ${ }^{14}$

Dois estudos, do tipo caso-controle, realizados na população britânica, mostraram uma associação entre os polimorfismos do gene MTHFR e a redução no risco de LLA. Skibola et al. relataram, em uma coorte de 71 casos de LLA de adulto, uma associação entre a susceptibilidade de desenvolver leucemia e os alelos polimórficos do gene MTHFR. ${ }^{4}$ Eles encontraram uma susceptibilidade diminuída em 4,3 vezes no risco de LLA $[O R=0,23(0,06-0,81)]$ para o alelo 677C. Este estudo também encontrou uma redução de 3 vezes no risco de LLA em indivíduos com o genótipo MTHFR $1298 \mathrm{AC}[\mathrm{OR}=0,33(0,15-0,73)]$, e de 14 vezes naqueles indivíduos com genótipo MTHFR 1298CC. Nenhuma associação estatisticamente significativa foi observada nos genótipos MTHFR 677 e 1298 quando eles compararam os casos de LMA com os controles. Embora em nosso estudo tenham sido analisados poucos casos de LMA, também não foi encontrada associação quando LMA foi comparada aos controles, corroborando com a hipótese de que os alelos polimórficos do gene MTHFR não desempenham papel no risco de LMA. O outro estudo, realizado por Wiemels et al., investigaram quais polimorfismos do gene MTHFR modificavam o risco de LA infantil em diferentes subgrupos, e observaram que crianças com genótipos MTHFR 677CT e 677TT (mas não os genótipos MTHFR 1298AC e 1298CC) estavam associados com a redução do risco de leucemias com translocação do gene MLL $[\mathrm{OR}=0,36(0,15-0,85) ; \mathrm{p}=0,017] \cdot 10$ Estes dados contrastam com aqueles obtidos em nosso trabalho, no qual não foi encontrada nenhuma associação no risco de LLA em crianças com o alelo MTHFR 677T ou com o alelo MTHFR 1298C. Em nosso estudo, a freqüência dos genótipos MTHFR 677TT e 1298CC foi de $10 \%$ e $8 \%$, respectivamente, as quais são consistentes com aquela encontrada nos controles. A falta de associação entre os genótipos MTHFR 677TT e 1298CC talvez possa ter sido influenciada pela alta prevalência do genótipo selvagem.

Uma vez que sabemos também que diversas campanhas já foram realizadas no Brasil, no intuito de que as gestantes tenham suplementação vitamínica durante o período pré-natal, foi especulado que o efeito nulo encontrado nos nossos resultados pode ser consequiência de um possível aporte de folato de forma satisfatória. Porém, como não há dados de uma enquete investigativa para análises combinadas e/ou multivariáveis, não podemos tirar nenhum resultado definitivo. Portanto, os genótipos variantes não mostram nenhum efeito na susceptibilidade a LA, sugerindo que outros mecanismos moleculares possuem maior importância na etiologia das leucemias agudas em crianças brasileiras. Krajinovic et al. mostraram, em um grupo de 270 crianças canadenses com LLA e 300 controles sadios, que a associação dos genótipos MTHFR 677TT/1298AA e 677CC/1298CC reduz o risco de LLA $[\mathrm{OR}=0,4(0,2-0,9)$; e OR = 0,3 $(0,1-0,6)$, respectivamente]. Neste trabalho, eles também mostraram que o efeito protetor das variantes polimórficas do gene MTHFR só está presente em crianças que nasceram antes da implementação de suplementação de folato durante a gestação. Mostrando mais uma vez a importância da interação gene-ambiente na susceptibilidade ao câncer. ${ }^{1}$

Assim como todos os estudos realizados anteriormente ${ }^{1,3,10,11} \mathrm{em}$ outras populações, este estudo também não encontrou a ocorrência simultânea dos dois genótipos mutantes (MTHFR 677TT/1298CC). A total ausência da associação de genótipos mutantes mostra que há uma relação de desequilíbrio entre os sítios 677 e 1298 variantes. A análise dos genótipos do MTHFR de neonatos e fetos revelou a presença do haplótipo 677T/1298C somente em fetos, e sua total ausência em neonatos, sugerindo que a presença da dupla mutação é incompatível com a vida. ${ }^{15}$

No estudo brasileiro, realizado anteriormente em 71 crianças com LLA, ao contrário dos nossos resultados, foi encontrada uma associação entre o alelo MTHFR 677T e a diminuição de 2,4 vezes o risco de LLA infantil. Entretanto, não foi observada nenhuma associação significativa entre o risco de LLA e o polimorfismo MTHFR $1298 .{ }^{16}$ Talvez o resultado de Franco et al. reflita uma amostra mais homogênea. No entanto, é importante ressaltar, que embora em nosso estudo tenham sido analisadas amostras provenientes de 4 regiōes distintas do Brasil, houve o cuidado de 
comparar caso e controle das mesmas regióes separadamente. Nós analisamos separadamente casos e controles de cada região brasileira, mas não foi observada associação estatisticamente significativa entre os polimorfismos do gene MTHFR e o risco para LA infantil. Estes resultados corroboram com um estudo realizado por Chiusolo et al. na Itália, onde foram analisados 174 adultos com LLA e 110 controles. Eles não encontraram nenhuma associação entre os diferentes polimorfismos e a susceptibilidade a LLA $(\mathrm{OR}=0,69$ IC 95\% 0,4-1,19 para MTHFR 677CT e OR $=0,99$ IC 95\% 0,50-1,97 para MTHFR 677TT, tendo o genótipo selvagem como referência). Os valores encontrados para o polimorfismo MTHFR 1298 foram de OR = 0,93 IC 95\% 0,56-1,53 para MTHFR 1298AC e de OR = 1,14 IC 95\% 0,36-3,61 para o genótipo MTHFR 1298CC, em relação ao genótipo MTHFR 1298AA. O interessante deste estudo, é que na população mediterrânea desta coorte, os hábitos alimentares são consistentes com uma dieta rica em ácido fólico. Estes resultados não corroboram com a sugestão de que aquelas populações que carregam o alelo variante para os dois polimorfismos do gene MTHFR apresentam diferente susceptibilidade de risco ao câncer. ${ }^{11}$

Nossos dados não mostram nenhuma associação entre os polimorfismos do gene MTHFR 677 e 1298 e a susceptibilidade a LA em crianças provenientes de diversas regiões brasileiras. Estudos futuros são necessários para uma melhor compreensão do status do folato na dieta, e sua influência nos polimorfismos do gene MTHFR em nossa população.

\section{REFERÊNCIAS}

1. Krajinovic M, Lamothe S, Labuda D, Lemieux-Blanchard E, Theoret Y, Moghrabi A, et al. Role of MTHFR genetic polymorphisms in the susceptibility to childhood acute limphoblastic leukemia. Blood. 2004;103(1):252-7.

2. Sinnett D, Krajinovic M, Labuda D. Genetic susceptibility to childhood acute lymphoblastic leukemia. Leuk Lymphoma. 2000;38(5-6):447-62.

3. Greaves MF. Childhood leukaemia. BMJ. 2002;324:283-7.

4. Skibola CF, Smith MT, Kane E, Roman E, Rollinson S, Cartwright RA, et al. Polymorphisms in the methylenetetrahydrofolate reductase gene are associated with susceptibility to acute leukemia in adults. Proc Natl Acad Sci U S A. 1999;96(22):12810-5.
5. Frosst P, Blom HJ, Milos R, Goyette P, Sheppard CA, Matthews RG, et al. A candidate genetic risk factor for vascular disease: a common mutation in methylenetetrahydrofolate reductase. Nat Genet. 1995;10(1):111-3.

6. Robien K, Ulrich CM. 5,10-Methylenetetrahydrofolate reductase polymorphisms and leukemia risk: a HuGe minireview. Am J Epidemiol. 2003;157:571-82.

7. Chen J, Giovannucci E, Kelsey K, Rimm EB, Stampfer MJ, Colditz GA, et al. A Methylenetetrahydrofolate reductase polimorphism and the risk of colorectal cancer. Cancer Res. 1996;56:4862-4.

8. Gershoni-Baruch R, Dagan E, Israeli D, Kasinetz L, Kadouri E, Friedman E. Association of the C677T polymorphism in the MTHFR gene with breast and/or ovarian cancer risk in Jewish women. Eur J Cancer. 2000;36:2313-6.

9. Esteller M, Garcia A, Martinez-Palones JM, Xercavins J, Reventos J. Germ line polymorphisms in cytochrome-P450 1A1 (C4887 CYP1A1) and methylenetetrahydrofolate reductase (MTHFR) genes and endometrial cancer susceptibility. Carcinogenesis. 1997;18(12):2307-11.

10. Wiemels JL, Smith RN, Taylor GM, Eden OB, Alexander FE, Greaves MF, et al. Methylenetetrahydrofolate reductase (MTHFR) polymorphisms and risk of moleculary defined subtypes of childhood acute leukemia. Proc Natl Acad Sci U S A. 2001;98:4004-9.

11. Chiusolo P, Reddiconto G, Cimino G, Sica S, Fiorini A, Farina G, et al. Methylenetetrahydrofolate reductase genotypes do not play a role in acute lymphoblastic leukemia pathogenesis in the Italian population. Haematologica. 2004;89(2):139-44.

12. Pui CH. In: Childhood leukemias. Cambridge: Cambridge University Press; 1999. p. 111-97.

13. Thompson JR, Gerald PF, Willoughby ML, Armstrong BK. Maternal supplementation in pregnancy and protection against acute lymphoblastic leukaemia in childhood: a casecontrol study. Lancet. 2001;358:1935-40.

14. Bailey LB. Folate, methyl-related nutrients, alcohol, and the MTHFR 677C--> T polymorphism affect cancer risk: intake recommendations. J Nutr. 2003;133(11 Suppl 1):3748S-53S.

15. Isotalo PA, Wells GA, Donnelly JG. Neonatal and fetal methylenetetrahydrofolate reductase genetic polymorphisms: an examination of C677T and A1298C mutations. Am J Hum Genet. 2000 Oct;67(4):986-90.

16. Franco RF, Simoes BP, Tone LG, Gabellini SM, Zago MA, Falcao RP. The methylenetetrahydrofolate reductase C677T gene polymorphism decreases the risk of childhood acute lymphocytic leukaemia. Br J Haematol. 2001;115:616-8. 
